\title{
Survivors of childhood sexual abuse: approaches to therapy
}

\section{Michael Crowe \& Christopher Dare}

The experience of sexual abuse in childhood is very common (Jehu, 1988). The highest estimate from the USA (Wyatt \& Peters, 1986) suggests that $42 \%$ of girls up to the age of 17 have experienced abuse, and the best estimate from Britain (Baker \& Duncan, 1985) would give a prevalence of between 12 and $20 \%$. Mullen et al (1993) found in a general population of women in New Zealand an overall prevalence of abuse before the age of 16 of $32 \%$, with $20 \%$ reporting genital contact and $3 \%$ penetrative sex. In the American series half of those abused ( $21 \%$ of the respondents) reported that the abuse was by a family member: the figure for intra-familial abuse in the British series was $14 \%$ of those reporting abuse, and thus about $3-5 \%$ of all the women who responded. There may be many explanations for the large international variations, including differences in definition, sampling and other aspects of methodology, but it is also possible that abuse is indeed more common in some countries than others.

There is no objective way of confirming or refuting the accuracy of the respondents' memories, especially those who have recovered the memory of previously forgotten events (Dare, 1993). However, even taking a conservative estimate of the situation there is a very large number of women, and a smaller but significant number of men (between 8 and 16\% of the population; Jehu, 1988), reporting sexual abuse in childhood.

\section{Consequences of sexual abuse}

The long-term consequences of sexual abuse are not easy to distinguish from other psychiatric syndromes, and a wide variety of symptoms is seen in those who report an abuse history (Staples \& Dare, 1996). One way to assess the significance of abuse is to compare the prevalence of various symptoms and behaviour patterns in those reporting prior sexual abuse with the general population figures. This has been done in a number of case reports and surveys, although the results of such exercises do not exclude the possibility that they may be the result of factors other than the sexual abuse, for example emotional deprivation or physical abuse. The usual interpretation, however, links the abuse causally to the symptoms (whether they be of the nature of posttraumatic stress or of damaged personal relationships) and these may be divided into those which can be seen as direct results of the abuse (e.g. flashbacks, nightmares about abuse and sexual phobias) and those which seem to be more indirectly linked (e.g. self-harm, depression and eating disorders). Box 1 indicates some of the postulated consequences of childhood sexual abuse.

Box 1. Long-term consequences of childhood sexual abuse

\begin{tabular}{|c|c|}
\hline Direct & Indirect \\
\hline Nightmares & Low self-esteem \\
\hline Flashbacks & Depression \\
\hline $\begin{array}{l}\text { Sexual phobias } \\
\text { and dysfunctions }\end{array}$ & $\begin{array}{l}\text { Self-harm } \\
\text { Self-hatred }\end{array}$ \\
\hline Anger & Suicidal behaviour \\
\hline Inability to trust & Bulimia nervosa \\
\hline $\begin{array}{l}\text { Choosing abusive } \\
\text { partners }\end{array}$ & $\begin{array}{l}\text { Substance misuse } \\
\text { Psychoses and }\end{array}$ \\
\hline Becoming an abuser & borderline states \\
\hline $\begin{array}{l}\text { Amnesia and } \\
\text { 'multiple personali }\end{array}$ & \\
\hline
\end{tabular}

Michael Crowe is a consultant psychiatrist and Honorary Senior Lecturer at Bethlem Maudsley NHS Trust (Maudsley Hospital, Denmark Hill, London SE5 8AZ). His interests are in behavioural and cognitive psychotherapy, sexual, marital and family therapy. He runs a unit for the therapy of people who repeatedly inflict self-harm and for abuse survivors. Christopher Dare is a reader in psychotherapy at the Institute of Psychiatry. He has a long-standing interest in the psychotherapy of disorders in adolescents and young adults, arising from childhood experiences of sexual abuse. 
It is important to remember that not all abused children go on to develop symptoms or disturbed behaviour in adult life. It has been found that in a community sample of women who had been incestuously abused $34 \%$ had suffered extreme trauma, $48 \%$ some trauma and $18 \%$ reported no trauma at all (Russell, 1983). The greater degrees of trauma are correlated with: longer duration of the abusive relationship; the use of force; closer relatedness of the abuser and the child; invasiveness of the sexual act; and the older the abused person is when the abuse stops.

In Mullen et al's (1993) report the women who had experienced penetrative abuse were significantly more likely to have eating disorders, anxiety, depression, suicidal behaviour and substance misuse than those who had experienced other forms of abuse, and between two and six times as likely to suffer psychiatric disorders than the nonabused control group. These figures, however, are subject to an interaction factor with other forms of deprivation: thus, those who had been abused and who had psychiatric symptoms as adults were also more likely to have suffered poor parenting, parental separation and to have been brought up in a nonnuclear family than controls. It is also suggested (Jehu, 1988) that a more secure adjustment in the victim before the abuse took place may be correlated with a better outcome after the abuse. However, these are only statistical findings and do not predict the individual response to a history of abuse.

The existence of a sexually abusive relationship implies the imposition on a child or adolescent of a sexual interaction which he or she cannot fully comprehend and to which he or she cannot emotionally or legally consent. The unique difficulty in a case of sexual abuse, as opposed to physical or emotional abuse, is that the child may respond in a physical, sexual sense to what is happening and enjoy the experience sensually, only later realising that it was wrong and that it had not happened to others. If the perpetrator of the abuse is a family member, especially a parent, conflicts may arise in the child, leading to feelings of guilt and self-blame. The responses of other members of the family, especially the non-abusive parent, are important, and a child who discloses information only to be disbelieved or told not to break up the family' is in a much worse situation than one who is treated sympathetically. Many children, realising the possible negative consequences of disclosure, prefer not to do so and keep the abuse a secret into adult life. In some cases they only disclose because it is thought that younger relatives may be at risk from the same abuser (for a case example of the management of such a situation see Dare, 1990).

\section{Management of disclosure}

The disclosure of past abuse is quite common in psychiatric practice, and needs to be handled with understanding and sympathy. It is especially important to avoid any implied disbelief or blame, or to minimise the impact of the abuse. On the other hand, over-reaction to the account of the experience or excessive curiosity about the details can also be harmful. It is helpful to remember that the victim may be very sensitive to anything in the therapeutic relationship which seems abusive: thus premature suggestions for action, such as confrontation of the abuser, should be avoided. It is preferable to allow the disclosure to proceed at the victim's own pace, and to remain non-judgemental at all stages of the process.

Dilemmas will arise in many cases where the victim asks about the advisability of taking the abuser to court or otherwise punishing him. Here the therapist is inevitably treading on very difficult ground. If she or he advises against court action, the person may feel betrayed and treated much as the family may have treated them in the past. However, if court action is encouraged, the person may be exposed to painful interrogation and counteraccusation, and if the case goes against the victim, they may feel worse afterwards than if the case had not been brought. Perhaps the most cogent reason to bring an abuser to court is if there are younger relatives still at risk of abuse, and the victim cannot find another way to protect them. This may be especially so in the case of disclosure of satanic ritual abuse or of paedophile rings. Where court action is undertaken, the therapist should be acutely aware of the risks that the survivor is taking, and provide appropriate support. In the UK, a professional has a mandatory responsibility to inform the relevant social services department that a juvenile (someone under the age of 18 years) has been subjected to sexual abuse.

There are many ways in which the general process of disclosure may be managed. It will vary to some extent according to the theoretical approach used by the therapist. However, whatever the theoretical basis of the therapy, it has to be remembered that these people are especially sensitive to the damaging effects of psychotherapy, and that the therapist has to move, if anything, more slowly and carefully than in other cases to avoid the possibility of being unintentionally abusive to the individual.

Another general consideration in the management of both disclosure and therapy is the gender of the therapist. The victim will often prefer the therapist to be a different gender from the abuser, 
and this is particularly so in those people who have had unusually severe abuse experiences, or those who find it impossible not to identify someone of the abuser's gender as being potentially abusive. Conversely, if a good therapeutic relationship can be built up with such a person, this may have a positive effect and accelerate improvement.

\section{General management of survivors}

Given the wide variety of conditions from which survivors of abuse may be suffering, the management of the abuse has to be modified to match the diagnosis. It is clearly appropriate to manage a victim of abuse suffering from schizophrenia with antipsychotic medication as well as supportive psychotherapy and specific abuse counselling for symptoms such as flashbacks and nightmares. The prime consideration is usually the psychiatric presentation, and only after acute or life-threatening symptoms have been controlled is it appropriate to deal with the after-effects of the abuse. Thus, people who present eating disorders, depression, anxiety, self-harm, suicidal behaviour, psychoses or substance misuse should be managed primarily for these problems and only then for the flashbacks or other specific effects of the abuse.

\section{Post-traumatic stress following abuse}

This approach treats the abuse as a trauma analogous to a car accident or a plane crash, but more damaging and at a more vulnerable age than most such traumas. The survivor is seen as someone who has lived through a series of traumatic events, which can have the after-effects of causing intrusive memories, nightmares or other sensory phenomena as well as "numbing general responsiveness to events in the external world" (DSM-III-R; American Psychiatric Association, 1987). In Dolan's (1991) approach this is dealt with by a combination of cognitive and solution-focused therapy. The general therapeutic stance is one of "replacing negative, selfdestructive expectations with a positive, yet realistic, vision of the future" (Dolan, 1991). A wide variety of techniques is employed to this purpose, including the utilisation of supportive family relationships, the management of feelings towards non-supportive family members and perpetrators, ensuring safety in the current situation, helping the victim to reduce dissociation and 'reclaim the body' and to carry out specific therapeutic tasks such as writing letters (not usually sent) to abusers and others. Linehan (1993) has a similar approach to sexual abuse therapy as part of her cogntive-behavioural treatment approach to personality disorders. She advocates avoiding too much disclosure until reasonable trust and stability has been achieved. At this stage the emphasis is on helping the person to accept and change current patterns of thought through a 'dialectic' discussion and not to bring the traumas into therapy until the patient can cope with the consequences of exposure to it. Later in therapy there is an emphasis on reducing self-hate and shame and on construing the person's own history and presenting it to others. Dolan (1991) reports some resolutions in two or three sessions, but therapy may continue for months or years, with an indefinite ending and the possibility of further follow-up sessions.

\section{Dealing with an abuse history in relationship problems}

It is not unusual for the disclosure of sexual abuse to occur in the context of a relationship problem or in the treatment of sexual dysfunction. This has been described by Douglas et al (1989) and a sequential programme of treatment has been advocated involving, as a first stage, the disclosure and resolution of the abuse issue with the survivor as an individual, and then more active couple therapy bringing the abuse issue in as part of the communication between the partners. Douglas and colleagues found, interestingly, that the survivor's level of depression remained quite high during the individual stage of therapy, but improved quite rapidly when the subsequent couple therapy helped the victim's partner to understand her distress and insecurity.

Jehu (1988) has also reported the management of abuse counselling in the context of couple therapy. He too has found that it is better in most cases to use both individual and couple therapy, although he seems to prefer to involve the partner as much as is feasible, in contrast to Douglas et al's elective exclusion of the partner from some of the therapy.

Jones (1993) has described a general approach to working with couples or with individuals using a family systems approach, which is especially relevant to the situation with survivors of childhood sexual abuse. Jones's especial sensitivity to the issues of gender-derived power relationships within 
society and the family is an essential component in exploring the experience of the abused victim.

\section{Psychodynamic approach}

It is notably ironic that Freud's original theoretical constructs concerning the origins of neurosis assumed a universal experience of sexual abuse in his subjects. Hence his first suggestions as to technique were addressed to the issue of therapeutic management of the survivors of childhood sexual abuse (Dare, 1993). Freud's observations inaugurated techniques to encourage an individual to 'discharge' the hitherto unexpressed feelings and to recover, as fully as possible, memories of abusive experiences. The notion of the therapeutic usefulness of such activities, in order that the painful states can be psychologically processed, remains an essential component of many counselling and psychotherapeutic approaches to the treatment of survivors of childhood sexual abuse. More recent psychoanalytic thinking (Sherkow, 1990), emphasises the complexity of the psychopathological organisations that derive from sexual abusive experiences.

As has been mentioned above, sexual abuse carries with it implications of arousal and physical responsiveness that can predispose the child to feelings of guilt and responsibility that are less likely when the violence is non-sexual. Painful and bewildering affects, and the defences against them, are the cornerstone of the psychodynamic understanding. Shame about the sexual contact, humiliation at the loss of control and exposure implicit in sexuality, fear of retribution and blame are all common and have a long-term role in subsequent personality development and symptom formation. Psychoanalytic therapy focuses upon enabling the person to work through the complex mixture of feelings. The careful management and interpretative exploration of an emergence of an 'abusing transference' is an important component of psychoanalytically informed work. The interest that the therapist has in being helpful, combined with the wish to know 'what is really gong on inside', can be experienced as intrusive and potentially abusive. This combination has a resemblance to the misuse of parental caring (e.g. washing, dressing, health checks) to make sexually abusive probing. Horowitz (1991) has written extensively upon brief, psychodynamic manualised treatment techniques, with particular reference to working with survivors of stressful events, which are especially useful with adults who have been sexually abused in childhood.

\section{Dealing with the families of victims}

Sexual abuse occurs either because an adult family member is sexually pathological, or because the usual provision of protection by parents has failed. Most survivors and their families are, therefore, likely to be significantly troubled in their mutual relationships.

It is widely acknowledged that the management of the family is, in practice, difficult, and diverse techniques have been developed (Jones, 1991; Bentovim \& Davenport, 1992; Roesler et al, 1993). There are a number of quite different problems: helping a child in a sexually abusive family; work with families within which extra-familial abuse has occurred; working with adults who have been sexually abused within or outside of the family in childhood. In all situations there is a need for an integration of individual counselling or psychotherapy plus work with the parental couple, work with a single parent and work with the whole family. Family acknowledgement of the trauma that has occurred or is occurring is an essential component but can be extremely difficult to achieve, not only because of the criminal charges that might ensue, but also because of the shame and fear of sexuality within these families. When working with abused children and their families the combination of involvement in legal processes as well as therapeutic work can cause difficulties for the family therapist (Crowther et al, 1990).

\section{Special situations}

In dealing with survivors who have particular difficulties there may be a need to use some specific approaches. Thus, in eating disorders, perhaps more often in victims with bulimia but also with anorexia, the existence of sexual abuse functions as a therapeutic complication of the disorder and, by clinical observation, appears to be associated with a worse prognosis. The treatment needs of the victim, in relation to the derivatives of abuse, are not demonstrably different from those of other patient groups.

In those survivors who show parasuicidal or selfmutilating behaviour there are some important points that should be emphasised. Self-harm is seldom simply a cry for help or attention-seeking. It is much more often explained as a way of expressing the person's self-hatred, of punishing 
the abuser or of simply relieving tension. In practice, attempts by staff to prevent the selfharm are usually ineffective except in the very short term, and experience with these people shows that it is more productive to leave much of the responsibility for maintenance of safety with the victim. This, in combination with carefully paced work on the abuse itself, which may at times include family discussions, would appear to give the best possibility of improvement in this very damaged group of people (futher details available from the author upon request; Crowe, 1997).

\section{Self-help groups for survivors}

One of the most promising approaches with survivors is the use of self-help groups. These are usually run by professionals such as community nurses or social workers, but leave a good deal of the support and help for individuals to other members of the group. Survivors themselves are in many ways best placed to provide help and understanding to other survivors, and there is often a need for urgent discussion of a crisis or problem, which can be provided by a fellow member of the group on the telephone between group sessions.

\section{Conclusions}

Healy (1993) has suggested that the identification of post-traumatic stress disorder represents a paradigm shift whereby psychogenesis has, in the course of the past 20 years, become intellectually acceptable. This can be linked to the parallel social change whereby sexual abuse in childhood can now be discussed. This horrendous trauma has come to figure large in the life story of a significant proportion of people with psychiatric disorders. Although it is difficult to demonstrate pathognomonic long-term effects, many individuals are sure that they have been specifically traumatised. The need for effective techniques to help the survivors have emerged with the 'epidemic' of disclosure. A range of treatments have been tried for the different derivatives: medication for the affective disturbance; cognitive interventions to counter the painful ideations; selfhelp groups for mutual support and to allow victims to identify the commonality of their state; couple interventions to address the sexual and relationship problems; family interventions to help express the unspeakable; and psychodynamic psychotherapy to explore and confront the existential despair and identity confusion. The diversity represents the multiplicity of the sequelae and the absence of a 'gold standard' treatment. There are few systematic studies to guide the practitioner for work with particular victims, and so clinical impressions and therapeutic habits dominate practice.

\section{References}

American Psychiatric Association (1987) Diagnostic and Statistical Manual of Mental Disorders (3rd edn, revised) (DSM-III-R). Washington, DC: APA.

Baker, A. W. \& Duncan, S. P. (1985) Child sexual abuse: a study of prevalence in Great Britain. Child Abuse and Neglect, 9, 457-467.

Bentovim, A. \& Davenport, M. (1992) Resolving the trauma organised system of sexual abuse by confronting the abuser. Journal of Family Therapy, 14, 29-50.

Crowe, M. (1997) deliberate self-harm. In Troublesome Disguises: Underdiagnosed Psychiatric Syndromes (eds D. Bhugra \& A. Munro), pp. 206-225. Oxford: Blackwells Science.

Crowther, C., Dare, C. \& Wilson, J. (1990) 'Why should we talk to you? You'll only tell the Court!' On being an informer and a family therapist. Journal of Family Therapy, 12, 105-122.

Dare, C. (1990) The psychodynamic therapy of children with emotional and behavioural difficulties. In The Management of Children with Emotional and Behavioural Difficulties (ed. V. P. Varma), pp. 18-40. London: Routledge.

- (1993) Denial and childhood sexual abuse. Journal of Forensic Psychiary, 4, 1-4.

Dolan, Y. (1991) Resolving Sexual Abuse. New York: W. W. Norton.

Douglas, A., Matson, I. C. \& Hunter, S. (1989) Sex therapy for women incestuously abused as children. Sexual and Marital Therapy, 4, 143-160.

Healy, D. (1993) Images of Trauma. London: Faber and Faber.

Horowitz, M. J. (1991) Short-term dynamic therapy of stress response disorders. In Handbook of Short-Term Dynamic Psychotherapy (eds P. Crits-Christoph \& J. P. Barber), pp. 166-198. New York: Basic Books.

Jehu, D. (1988) Beyond Sexual Abuse. Therapy with Women who were Childhood Victims. Chichester: John Wiley and Sons.

Jones, E. (1991) Working with Adult Survivors of Child Sexual Abuse. London: Karnac.

- (1993) Family Systems Therapy. Chichester: John Wiley and Sons.

Linehan, M. (1993) Cognitive Behavioural Treatment of Borderline Personality Disorder. New York: Guilford Press.

Mullen, P. E., Martin, J. L., Anderson, J. C., et al (1993) Childhood sexual abuse and mental health in adult life. British Journal of Psychiatry, 163, 721-732.

Roesler, T. A., Savin, D. \& Grosz, C. (1993) Family therapy of extra familial sexual abuse. Journal of the American Academy of Child and Adolescent Psychiatry, 32, 967-970.

Russell, D. E. H. (1983) The incidence and prevalence of intrafamilial and extra familial sexual abuse of female children. Child Abuse and Neglect, 7, 133-146.

Sherkow, S. P. (1990) Evaluation and diagnosis of sexual abuse of little girls. Journal of the American Psychoanalytic Association, 38, 347-370.

Staples, E. \& Dare, C. (1996) The impact of childhood sexual abuse. In Planning Community Mental Health Services for Women (eds K. Abel, M. Buszewicz, S. Davison, et al), pp. 145-159. London: Routledge.

Wyatt, G. E. \& Peters, S. D. (1986) Issues in the definition of child sexual abuse in prevalence research. Child Abuse and Neglect, 10, 231-240. 